\title{
The 'lipid raft' microdomain proteins reggie-I and reggie-2 (flotillins) are scaffolds for protein interaction and signalling
}

\author{
Claudia A.O. Stuermer ${ }^{1}$ and Helmut Plattner \\ Department of Biology, University of Konstanz, 78467 Konstanz, Germany
}

\begin{abstract}
Reggie-1 and reggie-2 are two evolutionarily highly conserved proteins which are up-regulated in retinal ganglion cells during regeneration of lesioned axons in the goldfish optic nerve. They are located at the cytoplasmic face of the plasma membrane and are considered to be 'lipid raft' constituents due to their insolubility in Triton X-100 and presence in the 'floating fractions'; hence they were independently named flotillins. According to our current view, the reggies subserve functions as protein scaffolds which form microdomains in neurons, lymphocytes and many other cell types across species as distant as flies and humans. These microdomains are of a surprisingly constant size of $\leqslant 0.1 \mu \mathrm{m}$ in all cell types, whereas the distance between them is variable. The microdomains co-ordinate signal transduction of specific cell-surface proteins and especially of GPI (glycosylphosphatidylinositol)-anchored proteins into the cell, as is demonstrated for $\operatorname{PrPc}^{\mathrm{c}}$ (cellular prion protein) in T-lymphocytes. These cells possess a pre-formed reggie cap scaffold consisting of densely packed reggie microdomains. $\mathrm{PrP}^{\mathrm{c}}$ is targeted to the lymphocyte reggie cap when activated by antibody cross-linking, and induces a distinct $\mathrm{Ca}^{2+}$ signal. In developing zebrafish, reggies become concentrated in neurons and axon tracts, and their absence, after morpholino antisense RNA-knockdown, results in deformed embryos with reduced brains. Likewise, defects in Drosophila eye morphogenesis occur upon reggie overexpression in mutant flies. The defects observed in the organism, as well as in single cells in culture, indicate a morphogenetic function of the reggies, with emphasis on the nervous system. This complies with their role as scaffolds for the formation of multiprotein complexes involved in signalling across the plasma membrane.
\end{abstract}

1To whom correspondence should be addressed (claudia.stuermer@uni-konstanz.de). 


\section{Introduction}

Reggie-1 and reggie-2 were discovered as two $48 \mathrm{kDa}$ proteins that are upregulated during axon regeneration of retinal ganglion cells following optic nerve lesion in goldfish and rats [1,2], suggesting an important role in axon growth and neuronal differentiation. On the other hand, their biochemical properties, such as insolubility in cold non-ionic detergents and presence in the 'floating' fraction after sucrose-density centrifugation, identifies reggies as 'lipid raft' proteins. Hence they were considered to be constituents of caveolae and were named flotillin [3]. Our analyses with LM and EM (light and electron microscopy respectively), however, defined reggies as non-caveolar microdomains of a surprisingly constant average size of $\leqslant 0.1 \mu \mathrm{m}[1,4-7]$. This is reflected by their typical punctate distribution along the plasma membrane, which extends into the finest cellular extensions in all cultured cells, including neurons, axons and filopodia (Figures 1A-1F) [1,4,5]. Reggies are associated with the cytoplasmic face of the plasma membrane via acylation [7,8], where they most likely exist as oligomers. Oligomerization of reggie-1 has been shown by velocity gradient centrifugation [7], and, since reggie-2 closely resembles reggie- 1 in the region that is involved in oligomerization, we expect that reggie- 1 and -2 associate to form hetero-oligomers, which in turn represent the $\leqslant 0.1 \mu \mathrm{m}$ microdomains of our microscopic analysis [1,5].

Reggies are evolutionarily highly conserved from flies to fish and humans $[9,10]$. This predicts an evolutionarily important and possibly conserved role of the reggies, but their exact function is not yet known. The fact that reggies are implicated in functions such as process formation in epithelial, glial and neuronal cell lines [5,7,11-13], cell-membrane-directed transport of GluT (glucose transporter) in adipocytes [14], correct positioning of neuronal cell-adhesion proteins [15], lymphocyte signalling and cell division [5,16] suggests a very basic cellular function. Indeed, pathways involving flotillin-1 (reggie-2) and leading to actin cytoskeleton rearrangement have been proposed $[14,17]$. There is accumulating evidence that reggies have a developmentally early and a later, spatio-temporally restricted expression in the organisms [15,18], becoming concentrated mainly in neurons and axon tracts, and in addition in lymphocytes $[4,5,16]$ and other blood cells [19]. This is consistent with their original isolation from brain $[2,3]$. In the present review, we suggest a unifying view for the role of reggies in light of these diverse functional aspects.

We have analysed the reggies in various cell types, most carefully in human lymphocytes, neuronal cells, zebrafish embryos and Drosophila $[1,15,18]$. Based on this work and together with suggestions concerning the role of podocin [20-23] and stomatin [19] (which are, like reggies, members of a superfamily of structurally related proteins [24]), we propose that reggie-1 and -2 form hetero-oligomeric co-clusters and scaffolds that promote the focal concentration and interaction of specific cell-surface and intracellular signal transduction proteins. The existence of such conspicuous microdomains in almost all cells, their dynamic rearrangement in specific situations and association with sets of cellular recognition and signalling proteins suggests that 

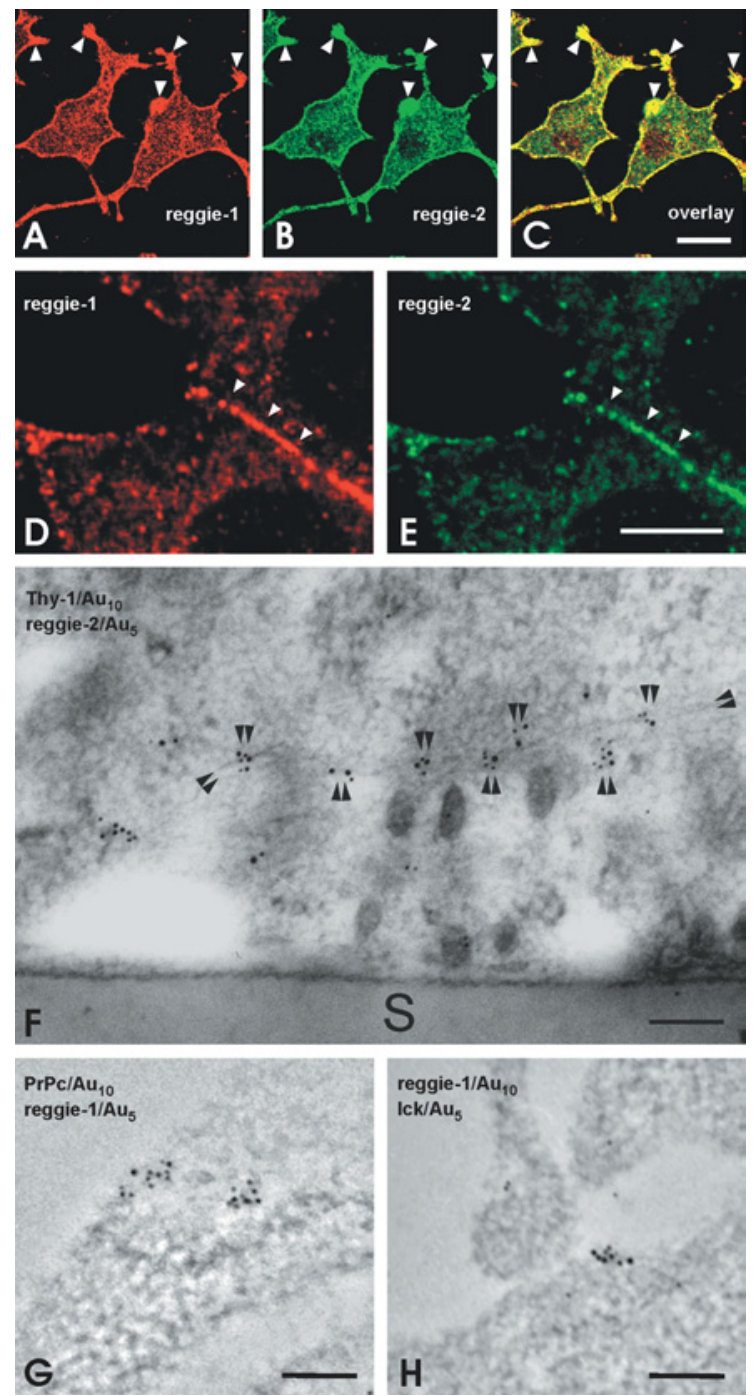

Figure 1 Reggie microdomains and associated proteins at the plasma membrane of PCI 2 and T-cells. Reggie-I (A) and reggie-2 (B) are co-localized $(\mathbf{C})$ in plasma membrane microdomains in $\mathrm{PCI} 2$ cells and are enriched in growth-cone-like processes (arrowheads) and filopodia. Microdomains of reggie-I (D) and reggie-2 (E) occur in increased density at cell-cell contact sites. Scale bars, 5 um. (F) Double immuno-EM image showing co-clusters of Thy-I and reggie- 2 which are co-localized in $\leqslant 0.1 \mu \mathrm{m}$ microdomains of increased density at cell-cell contact sites. (D, E and F) are reprinted from the Molecular Biology of the Cell (200I) 12, 303I-3045, with permission by the American Society for Cell Biology. (G, H) In T-lymphocytes, stimulated by antibody cross-linking of $\mathrm{PrP}^{\mathrm{c}}$, aggregates of $\mathrm{PrP}^{\mathrm{c}}$ are observed which co-localize with reggie-I (G), and reggie-I in turn co-clusters with the tyrosine kinase Ick $(\mathbf{H})$, demonstrating the formation of multiprotein signalling complexes in reggie microdomains. Scale bars, $0.1 \mu \mathrm{m}$. 
reggies build up scaffolds for the assembly and signal transduction of multiprotein complexes at strategic sites (see below).

\section{Reggie caps in T-lymphocytes and signal transduction by $\operatorname{PrP}^{c}$ (cellular prion protein)}

Consistent with our view that reggies form microdomains and pre-formed signalling centres in neurons [5] is the pattern of reggie expression in T-lymphocytes $[5,16]$. Reggie-1 and reggie- 2 are concentrated in one aspect of Jurkat T-cells and T-cells isolated from human blood, and represent pre-formed scaffolds, where proteins involved in T-cell activation and signalling assemble in a process known as capping. Importantly, the reggies occupy this cap position before any stimulation, and thus represent pre-formed cap scaffolds much like the signalling platforms composed of reggie-1 and -2 in neurons $[5,16]$.

It has long been known that GPI (glycosylphosphatidylinositol)-anchored proteins, such as Thy-1, cluster and undergo capping in T-cells when activated by antibody cross-linking $[25,26]$. It has also been shown that GPI-anchored protein cross-linking induces signal transduction across the plasma membrane, involving the Src family tyrosine kinases fyn and lck, and leading to the rearrangement of the actin cytoskeleton, which in turn promotes the local accumulation of $\mathrm{T}$-cell receptor components $[4,26]$.

Jurkat T-cells also express the GPI-anchored $\operatorname{PrP}^{c}$, and we examined if $\mathrm{PrP}^{\mathrm{c}}$ cross-linking would induce $\operatorname{PrP}^{\mathrm{c}}$ capping, co-capping with the pre-formed reggie cap scaffolds and signal transduction with reorganization of the cytoskeleton. Indeed, antibody cross-linking in Jurkat T-cells resulted in $\operatorname{Pr} \mathrm{P}^{\mathrm{c}}$ aggregates that were concentrated in the cap region, and co-localized with reggie [4]. This assembly also led to an increase of fyn, lck (Figure 1H), LAT (linker for activation of T-cells), tyrosine phosphorylation of proteins, and Factin (filamentous actin) in the cap region, thus implying that $\operatorname{PrP}^{c}$ in association with reggie induces signal transduction. This was demonstrated directly by recordings of the intracellular $\mathrm{Ca}^{2+}$ concentration during $\mathrm{PrP}^{\mathrm{c}}$ cross-linking, which showed a brief distinct $\mathrm{Ca}^{2+}$ pulse [4], together with moderate phosphorylation of the MAPK (mitogen-activated protein kinase). When the $\mathrm{Ca}^{2+}$ signal was blocked, $\mathrm{PrP}^{\mathrm{c}}$ aggregates formed, but were widely distributed over the cell's circumference instead of being concentrated in the cap. Notably, the pre-formed reggie cap remained [4].

This implies that signals evoked by $\mathrm{PrP}^{\mathrm{c}}$ cross-linking promote the focal concentration of $\operatorname{Pr}^{\mathrm{c}}$ aggregates in regions of the reggie cap. This involves actin cytoskeletal reorganization ([25], and C.A.O. Stuermer, A. Reuter and H. Plattner, unpublished work). Furthermore, this result shows the participation of $\mathrm{PrP}^{\mathrm{c}}$ in signal transduction in T-lymphocytes and emphasizes the importance of scaffolding molecules such as the reggies. Reggie caps accumulate specific sets of proteins. They contribute to the transmission of signals by concentrating $\operatorname{PrP}^{\mathrm{c}}$, and thereby enhance protein interactions and communication with signal transduction molecules which are guided to these sites.

This result opens new perspectives for the analysis of $\mathrm{PrP}^{c}$ functions which may only become clear in the context of its interactions in cell-specific protein 
complexes. Studying $\operatorname{PrPc}^{\mathrm{c}}$ in association with reggie scaffolds and proteins that preferentially co-cluster with them is a promising approach. It is not yet known if the misfolded $\operatorname{PrP}$ scrapie conformer associates with reggie scaffolds in T-lymphocytes. This knowledge is relevant for two reasons: misfolded $\operatorname{PrP}$ scrapie may lose its capability of clustering in reggie microdomains and of undergoing appropriate protein interactions, leading to the well-known fatal disease $[27,28]$. Moreover, since blood cells reach every single organ, PrP scrapie in T-cells could promote scrapie propagation.

Whether such association of $\mathrm{PrPc}^{\mathrm{c}}$ and reggies exists in neurons is currently under investigation in PC12 and N2A cells. To this end, it is safe to say that a fraction of these cells indeed shows a close correlation in the distribution of reggie and $\mathrm{PrP}^{\mathrm{c}}$.

\section{Neurons}

Reggie-1 and reggie- 2 exhibit a strikingly punctate distribution indicative of microdomains in neurons and neuronal cell lines (Figures 1A-1E), and these microdomains have, according to LM and EM analyses using double labelling with antibodies, a constant 'unit size' of approx. $0.1 \mu \mathrm{m}$ (Figures 1D-1H), regardless of whether the cells were stimulated by cross-linking of GPIanchored proteins (Figures $1 \mathrm{~F}-1 \mathrm{H}$ ) or not [4,5]. These microdomains reach into axons, growth cones and filopodia [4,29], and, while their unit size remains constant, the distance between them is often reduced [5]. At strategic sites, the microdomains become more closely spaced (Figures 1D-1F), i.e. at cell-cell contact sites and in growth-cone-like extensions of PC12 cells (Figures 1A-1C). This suggests that cells can regulate the density of reggie microdomains [30] and provide many reggie microdomain scaffolds to sites of cell communication, adhesion, motility and growth [5]. That microdomain density and the concentration of reggie- 1 and -2 are regulated according to the actual 'needs' of the cell and its processes is consistent with the original discovery of the reggies: proteins highly up-regulated during retinal axon regeneration in fish [2].

The impression that reggie expression is adapted to actual requirements [30] is confirmed by the analysis of their expression pattern in developing zebrafish embryos $[10,18]$. Here, reggies turned out to be maternal transcripts, first present in the fertilized egg, then in all cells during cell division and gastrulation, now through expression by the embryo proper, suggesting an early function of the reggies. A few hours later, reggies become particularly relevant for neuronal development, as is suggested by their presence in all neurons and developing axon tracts in the 1.5-5-day embryo. In fact, reggie staining in the nervous system closely resembles labelling with pan-neuronal markers that identify the typical scaffold of tracts and commissures in the embryo [18]. This spatially and temporally highly regulated expression of reggies during nervous system development in the organism not only implies a function in neuronal differentiation, axon growth and growth cone pathfinding, but also emphasizes their very strict regulation, which was unexpected from their presence in basically every cell tested in culture. 


\section{Which functions do reggies have?}

Aside from scaffolding and signalling functions associated with T-cell caps and neuronal microdomains, new experiments with reggie siRNA (small interfering RNA) in HeLa cells, with morpholino knockdown approaches (a modified anti-sense RNA strategy) in zebrafish and with Drosophila mutants suggest a morphogenetic role of reggies in cells and organisms. Reggie and the proteins associating with them seem to contribute to actin cytoskeletal rearrangements, and, thereby, to so apparently diverse aspects as cell-shape control, adhesion, growth cone and filopodia formation and motility, as well as intracellular transport and protein targeting/positioning events.

\section{Morphogenetic functions of reggie-I and reggie-2 revealed by siRNA-treated HeLa cells}

To determine if and into which direction down-regulation of reggie expression affects cells, we initiated experiments with reggie-1- and reggie-2specific siRNA constructs which block protein translation. The most consistent results were obtained with HeLa cells [11]. Blockade of reggie-1 and -2 synthesis in siRNA-treated cells caused a reduction in reggie-1 and -2 protein concentration according to semi-quantitative Western blots. Plated cells changed their morphology quite strikingly by 3-4 days. Whereas the cells possess a more or less continuous row of filopodia on one side, they begin to distribute these filopodia to the tips of finger-like processes, which, in some cells, reached considerable length and led to cells of unusual shape. Control siRNA-treated cells did not show such effects. Reggie expression is apparently crucial for the formation and/or maintenance of processes, the distribution of filopodia and cell-shape control. This is consistent with a potential link of the reggies to the cytoskeleton $[4,17]$.

\section{Morphogenetic functions of reggie-I and reggie-2 in zebrafish}

The expression analysis of reggies in the developing zebrafish nervous system led us to expect severe defects in result of the inhibition of reggie protein synthesis. We employed the morpholino knockdown approach in zebrafish embryos to block protein translation, and examined the emerging defects.

Zebrafish embryos developing from reggie-1 and -2 morpholino-injected eggs exhibited severe abnormalities [18]. The first defects were noted during gastrulation. From 1 day onwards, and persisting over the subsequent days, were brain defects, significantly reduced brain size, immobility, and embryos with severely malformed heads and tails [18], whereas control morpholinoinjected embryos were normal. This is fully in line with the view that reggies are involved in the co-ordination of interacting molecular components promoting signal transduction, and thereby they contribute to various aspects of cell-cell interaction dependent events: cell division, cell-shape changes and neuronal differentiation, i.e. morphogenetic events. 


\section{Reggie in Drosophila}

In Drosophila, reggies are also lipid-raft-associated proteins, and are of functional relevance during nervous system development [15]. Antibody staining revealed that reggie proteins are highly enriched in axon fascicles, e.g. in the chiasmata of the optic lobe, which would be consistent with a role in cell adhesion. However, the P-element mutant for reggie-1 that lacks reggie-1 and has lost most of the reggie-2 protein did not show any obvious phenotype [15]. Yet it indicated that the reggie-2 protein requires reggie- 1 for its stabilization which was then confirmed directly. Moreover, overexpression studies showed a functional contribution of reggies to appropriate positioning of the cell-adhesion molecule irreC-rst (irregular chiasm $C$ roughest) in the eye [15]. By overexpressing reggie-1 or reggie-1 together with reggie- 2 in the eye imaginal disc, we were able to interfere with ommatidial sorting that involves the cell-adhesion molecule irreC-rst (and its relatives) [31-33], and its highly restricted expression in the apical cell-adhesion belt. Together with reports $[6,34-36]$ that show an association of homologous proteins with the reggie-related scaffolding protein podocin, a role of the reggie proteins in the establishment or co-ordination of multimolecular complexes in microdomains and communication across the plasma membrane is being supported.

\section{Modelling}

Interesting multimolecular complexes around the lipid raft scaffolding protein podocin were reported in slit diaphragm formation in human kidney cells $[21,22,34,37]$. Podocin belongs to the same superfamily as reggie- 1 and reggie-2 $[24,34]$, and provides microdomains for two large cell-adhesion proteins of the immunoglobulin superfamily [IgCAMs (Ig superfamily cell-adhesion molecules)], i.e. nephrin and Neph which undergo heterophilic binding like their Drosophila relatives irreC-rst and SnS (sticks and stones)/hibris [31-33,38]. These IgCAMs in turn are distantly related to zebrafish and goldfish neurolin, which functions in eye morphogenesis and retinal growth cone guidance and regeneration [39,40]. Nephrin and Neph are strictly localized to the apical side of the podocyte's filopodia-like extensions which is marked by podocin $[20,34]$. It appears likely that podocin forms a scaffold much like reggies do in the many other cells discussed above. The Drosophila IgCAMs irreC-rst and SnS/hibris, as well as Nephrin and Neph1 possess large intracellular domains which undergo interactions with Src family tyrosine kinases and adaptor proteins, such as CIN (Cbl-interacting protein) in case of the podocyte [20,34-36], to regulate the actin cytoskeleton, directly or via a series of other proteins.

A multiprotein signalling complex that regulates the actin cytoskeleton and is centred on the reggie scaffolds is depicted in Figure 2. Our results are derived from experiments with Thy-1, $\mathrm{PrPc}^{\mathrm{c}}$ and other GPI-anchored proteins which signal across the plasma membrane through their association with reggie scaffolds, Src tyrosine kinases and adaptor proteins (Figure 2). It is very likely that such multiprotein complexes can harbour a mixed population of interacting GPI-anchored and transmembrane proteins (Figure 2), depending on the cell 


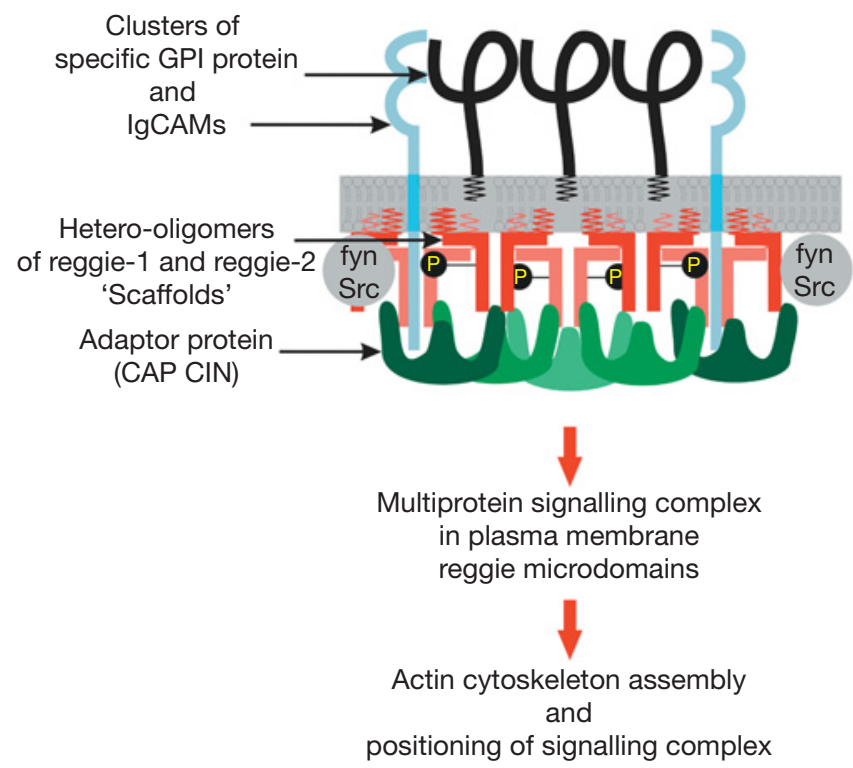

Figure 2 Reggie scaffolds and associated proteins. Our model proposes the existence of scaffolds consisting of hetero-oligomeric clusters of reggie-I and reggie-2 (red T bars) in microdomains at the cytoplasmic face of the plasma membrane. The membrane association of reggies via acylation is shown by the red jagged features, and their (still unproven) phosphorylation by P. Specific GPIanchored proteins, such as $\mathrm{PrPc}$ and Thy-I (black structures), co-cluster with the reggie scaffolds upon activation, and become capable of transmitting signals across the plasma membrane leading to a $\mathrm{Ca}^{2+}$ signal, Src tyrosine kinase activation, modified phosphorylation of the reggies and recruitment (or activation) of adaptor proteins (green) such as CAP (c-Cbl-associated protein) or CIN which effect actin cytoskeleton rearrangement via a series of intracellular proteins. It is possible that transmembrane proteins (light blue) also associate with the reggie scaffolds to contribute to or modify the multiprotein signal transduction cascade.

type and the affinity of the proteins to reggie scaffolds. It appears reasonable to assume that podocin recruits its specific partners for kidney morphogenesis and function, whereas reggies recruit their partners for nervous system morphogenesis and lymphocyte signalling. This implies evolutionary conservation of multiprotein signalling complexes and their scaffolds, from flies to fish and humans. Other members of the scaffolding protein family, such as stomatin [24], perform related functions in Caenorbabditis elegans morphogenesis and are important for the proper positioning of touch-receptor-associated ion channels [41]. We would predict similar functions for the remaining members of the family, such as prohibitin. Such a role of the reggie scaffolding proteins would account for their presence in different cell types, together with their role in differentiation, signalling and their evolutionary conservation.

This view is consistent with the original concept of signalling of GPIanchored proteins via clustered lipid rafts although 'classical' rafts (distinct 
from caveolae) have not been considered as elements that are stabilized by scaffolding proteins [26] nor to form pre-formed signalling centres [5] or pre-formed caps [16]. Rather, new biophysical methods to estimate raft size and mobility suggest a quite different view: rafts being tiny regions with fewer than a dozen of inhabitants that cannot be resolved at the microscopic level $[42,43]$. More significantly, membrane rafts are thought to be found predominantly in the outer leaflet of the plasma membrane $[26,43]$. In contrast, our current view on reggies emphasizes their larger unit size $(0.1 \mu \mathrm{m})$, presence on the cytoplasmic face of the plasma membrane and role as scaffolds for the formation of multiprotein complexes, involved in signalling across the plasma membrane upon ligand binding and communication with neighbouring cells.

We thank Dr Joachim Hentschel and Christopher Bleck for image composition, and Dr Alexander Reuter, Dr Edward Màlaga-Trillo and Matthias Langhorst for comments on the manuscript. Our work has been supported by the Ministerium Wissenschaft und Kunst (MWK) Baden-Württemberg, TSE programme, TR SFB 11 of the Deutsche Forschungsgemeinschaft (DFG) and Fonds der Chemischen Industrie (FCI).

\section{References}

1. Lang, D.M., Lommel, S., Jung, M., Ankerhold, R., Petrausch, B., Laessing, U., Wiechers, M.F., Plattner, H. and Stuermer, C.A.O. (1998) J. Neurobiol. 37, 502-523

2. Schulte, T., Paschke, K.A., Laessing, U., Lottspeich, F. and Stuermer, C.A.O. (1997) Development 124, 577-587

3. Bickel, P.E., Scherer, P.E., Schnitzer, J.E., Oh, P., Lisanti, M.P. and Lodish, H.F. (1997) J. Biol. Chem. 272, 19793-19802

4. Stuermer, C.A.O., Langhorst, M., Wiechers, M., Legler, D., Hannbeck von Hanwehr, S., Guse, A. and Plattner, H. (2004) FASEB J., in the press

5. Stuermer, C.A.O., Lang, D.M., Kirsch, F., Deininger, S., Wiechers, M.F. and Plattner, H. (2001) Mol. Biol. Cell 12, 3031-3045

6. Sumant, S.C., Kaw, B. and Kanwar, Y.S. (2003) Semin. Nephrol. 23, 544-555

7. Neumann-Giesen, C., Falkenbach, B., Rajendran, L., Lüers, G., Illges, H., Stuermer, C.A.O., Herzog, V. and Tikkanen, R. (2004) Biochem. J. 378, 509-518

8. Morrow, I.C., Rea, S., Martin, S., Prior, I.A., Prohaska, R., Hancock, J.F., James, D.E. and Parton, R.G. (2002) J. Biol. Chem. 277, 48834-48841

9. Galbiati, F., Volonté, D., Goltz, J.S., Steele, Z., Sen, J., Jurcsak, J., Stein, D., Stevens, L. and Lisanti, M.P. (1998) Gene 210, 229-237

10. Màlaga-Trillo, E., Laessing, U., Lang, D.M., Meyer, A. and Stuermer, C.A.O. (2002) J. Mol. Evol. 54, 235-245

11. Haenisch, C. (2004) Ph.D. thesis, University of Konstanz

12. Hazarika, P., Dham, N., Patel, P., Cho, M., Weidner, D., Goldsmith, L. and Duvic, M. (1999) J. Cell. Biochem. 75, 147-159

13. Schroeder, W., Stewart-Galetka, D.S., Parry, D.A., Goldsmith, D. and Duvic, M.L. (1994) J. Biol. Chem. 269, 19983-19991

14. Baumann, C.A., Ribon,V., Kanzaki, M., Thurmond, D.C., Mora, S., Shigematsu,S., Bickel, P.E., Pessing, J.E. and Saltiel, A.R. (2000) Nature (London) 407, 202-207

15. Höhne, M. (2003) Ph.D. thesis, University of Freiburg

16. Rajendran, L., Masilamani, M., Solomon, S., Tikkanen, R. and Stuermer, C.A.O. (2003) Proc. Natl. Acad. Sci. U.S.A. 100, 8241-8246 
17. Kioka, N., Ueda, K. and Amachi, T. (2002) Cell Struct. Funct. 27, 1-7

18. Màlaga-Trillo, E., Rivera-Milla, E., Marx, M., Bastmeyer, M. and Stuermer, C.A.O. (2002) Society for Neuroscience Abstract A30

19. Salzer, U. and Prohaska, R. (2001) Blood 97, 1141-1143

20. Chugh, S.H., Kaw, B. and Kanwar, Y. (2003) Semin. Nephrol. 23, 544-555

21. Schwarz, K., Simons, M., Reiser, J., Saleem, M.A., Faul, C., Kriz, W., Shaw, A.S., Holzman, L.B. and Mundel, P. (2001) J. Clin. Invest. 108, 1621-1629

22. Sellin, L., Huber, T.B., Gerke, P., Quack, I., Pavenstädt, H. and Walz, G. (2003) FASEB J. $17,115-117$

23. Shih, N.-Y., Li, J., Karpitskii, V., Nguyen, A., Dustin, M.L., Kanagawa, O., Miner, J.H. and Shaw, A.S. (1999) Science 286, 312-315

24. Tanaverakis, N., Driscoll, M. and Kyprides, N.C. (1999) Trends Biochem. Sci. 24, 425-427

25. Harder, T., Scheiffele P., Verkade, P. and Simons, K. (1998) J. Cell Biol. 141, 929-942

26. Simons, K. and Toomre, D. (2000) Nat. Mol. Cell Biol. 1, 31-39

27. Prusiner, S.B. (1995) Proc. Natl. Acad. Sci. U.S.A. 95, 13363-13383

28. Weissmann, C. (1999) J. Biol. Chem. 274, 3-6

29. Deininger, S.O., Rajendran, L., Lottspeich, F., Przybylski, M., Illges, H., Stuermer, C.A.O. and Reuter, A. (2003) Mol. Cell. Neurosci. 22, 544-554

30. López-Cases, P.P. and del Mazo, J. (2003) FEBS Lett. 555, 223-228

31. Dworak, H.A. and Sink, H. (2002) BioEssays 24, 591-601

32. Eroglu, C., Brügger, B., Wieland, F. and Sinning, I. (2003) Proc. Natl. Acad. Sci. U.S.A. 100, 10219-10224

33. Taylor, M.V. (2004) Curr. Biol. 13, R964-R966

34. Huber, T.B., Simons, M., Hartleben, B., Sernetz, L., Schmidts, M., Gundlach, E., Saleem, M.A., Walz, G. and Benzing, T. (2004) Hum. Mol. Genet. 12, 3397-3405

35. Jalanko, H. (2003) Pediatr. Nephrol. 18, 487-491

36. Li, C., Ruotsalainen, V., Tryggvason, K., Shaw, A.S. and Miner, J.H. (2000) Am. J. Physiol. Renal. Physiol. 279, F785-F792

37. Putaala, H., Soininen, R., Kilpeläinen, P., Wartiovaara, J. and Tryggvason, K. (2001) Human Mol. Genet. 10, 1-8

38. Strünkelnberg, M., De Couet, H.G., Hertenstein, A. and Fischbach, K.-F. (2003) J. Mol. Evol. 56, 187-197

39. Leppert, C.A., Diekmann, H., Paul, C., Laessing, U., Marx, M., Bastmeyer, M. and Stuermer, C.A.O. (1999) J. Cell Biol. 144, 339-349

40. Paschke, K.A., Lottspeich, F. and Stuermer, C.A.O. (1992) J. Cell Biol. 117, 863-875

41. Sedensky, M.M., Siefker, J.M. and Morgan, P.G. (2001) Am. J. Physiol. Cell Physiol. 280, C1340-C1348

42. Munro, S. (2003) Cell 115, 377-388

43. van Meer, G. (2004) Traffic 5, 211-212 